\title{
Integrating Information Technologies Into Large Organizations
}

\author{
Gretchen L. Gottlich \\ John M. Meyer \\ Michael L. Nelson \\ NASA Langley Research Center, Hampton VA \\ David J. Bianco \\ Computer Sciences Corporation, Hampton VA
}

This is a pre-print version of Chapter 17 in

Cases on Information Technology Management in Modern Organizations,

J. Liebowitz and M. Khosrowpour (eds.),

Idea Group Publishing, 1997, pp. 209 - 224. 


\title{
Integrating Information Technologies Into Large Organizations
}

\author{
Gretchen L. Gottlich \\ John M. Meyer \\ Michael L. Nelson \\ NASA Langley Research Center, Hampton VA \\ David J. Bianco \\ Computer Sciences Corporation, Hampton VA
}

\section{EXECUTIVE SUMMARY}

NASA Langley Research Center's product is aerospace research information. To this end, Langley uses information technology tools in three distinct ways. First, information technology tools are used in the production of information via computation, analysis, data collection and reduction. Second, information technology tools assist in streamlining business processes, particularly those that are primarily communication based. By applying these information tools to administrative activities, Langley spends fewer resources on managing itself and can allocate more resources for research. Third, Langley uses information technology tools to disseminate its aerospace research information, resulting in faster turn around time from the laboratory to the end-customer.

This paper describes how information technology tools are currently cutting cost and adding value for NASA Langley internal and external customers. Three components from a larger strategic WWW framework are highlighted: Geographic Information Systems (GIS), Integrated Computer Environment (ICE), and LANTERN (Langley's Intranet). Based on experiences with these and related projects at Langley, we suggest that there are four pillars of information technology project success: training; provision of useful services; access to enabling tools; and advertising and advocacy.

\section{BACKGROUND}

Established in 1917 as the first national civil aeronautics laboratory, Langley 's mission is to be a world leader in pioneering aerospace science and innovative technology for U.S. aeronautical and space application. The Center is dedicated to serving traditional aerospace customers and to transferring aerospace technology to non-traditional customers in response to changing national priorities. 
More than half of Langley's effort is in aeronautics, improving today's aircraft and developing ideas and technology for future aircraft. The center's wind tunnels and other unique research facilities, testing techniques and computer modeling capabilities aid in the investigation of the full flight range -- from general aviation and transport aircraft through hypersonic vehicle concepts.

The Center manages a dynamic program in atmospheric sciences, investigating the origins, chemistry and transport mechanisms that govern the Earth's atmosphere. A key component of this study is to understand the impact of human activity on our planet. Langley is also contributing to the development of the Earth Observation System (EOS), a major part of the international Mission to Planet Earth.

To better reflect the needs of its customers the Center has recently implemented a major reorganization of its management and operating structure consisting of: customer interface groups; a Research Group and an Internal Operations Group. Langley Research Center is a world class research laboratory which has a staff of well trained and highly productive scientists, engineers and support personnel, as shown in Tables 1 \& 2 (Office of Public Affairs, 1995).

\begin{tabular}{|l|c|c|}
\hline \multicolumn{1}{|c|}{ Function } & Number & \% of Workforce \\
\hline Scientific/Engineering & 1,256 & $50.0 \%$ \\
\hline Administrative & 271 & $11.0 \%$ \\
\hline Tech/Craft/Production & 757 & $30.1 \%$ \\
\hline Clerical & 224 & $8.9 \%$ \\
\hline
\end{tabular}

Table 1: Skill Mix (1995 data) 
Table 2: Formal Education Distribution (1995 data)

\begin{tabular}{|l|c|c|}
\hline \multicolumn{1}{|c|}{ Degree } & Number & \% of Workforce \\
\hline Doctoral & 282 & $11.2 \%$ \\
\hline Master & 573 & $22.8 \%$ \\
\hline Bachelor & 647 & $25.8 \%$ \\
\hline Associate & 469 & $18.7 \%$ \\
\hline Some college & 260 & $10.4 \%$ \\
\hline H.S. Diploma & 268 & $10.7 \%$ \\
\hline Other & 9 & $0.4 \%$ \\
\hline
\end{tabular}

Other pertinent workforce facts include:

- Civil Service Employees 2,508 (Fiscal Year 1995)

- Contract Employees 1,975 (Fiscal Year 1995)

- Fiscal Year 1994 total procurements: US \$525,000,000

- Fiscal Year 1995 Payroll: US \$144,500,000 (includes all compensation)

- Total Program Year 1995 Budget: US \$643,700,000

The NASA Langley Research Center occupies 787 acres of government-owned land and shares aircraft runways, utilities and some facilities with neighboring Langley Air Force Base. The center's more than 220 buildings represent an original investment of $\$ 687$ million and have a replacement value of over US $\$ 2$ billion. Langley's experimental facilities are: aerothermodynamic, subsonic, transonic, supersonic and hypersonic wind tunnels as well as scramjet engine tunnels. Langley's unique facilities include:

- Nation's only large flight Reynolds Number transonic tunnel

- Nation's only transonic dynamic loads/flutter tunnel

- Nation's only aerodynamic spin tunnel

- Nation's only high-Reynolds Number supersonic quiet tunnel

- Nationally unique aircraft landing loads and impact dynamics facility

- Highly specialized aero structures and materials research laboratories

Langley's 30 wind tunnels cover the entire speed range from $0 \mathrm{mph}$ to nearly Mach 25 . In addition to these uniquely facilities, Langley houses facilities for structures, materials and acoustics research, flight electronics, flight systems, simulators, simulation facility components, and a scientific and general purpose computing complex. 


\section{SETTING THE STAGE}

NASA Langley Research Center's product is aerospace research information and its production can depicted by the data relation model in Figure 1. Due to the technical nature of Langley's work, use of some information technology tools at Langley was already common place. A campus-wide Transmission Control Protocol / Internet Protocol (TCP/IP) network, known as "LaRCNET" (Shoosmith, 1993), has been in place since 1986, and use of e-mail, USENET news, file sharing, and other electronic communications were wide spread.

Langley uses information technology tools in three distinct ways in the production cycle of aerospace information. First, information technology is used in a variety of methods during research: computation, analysis, data collection, data reduction, etc. (Wieseman, 1994). Second, Langley uses information technology tools to assist in streamlining its business processes, especially those that are communication based. By applying these information tools to administrative activities, Langley spends fewer resources on managing itself and can allocate more resources for research. Lastly, Langley uses information technology tools to disseminate its information. Depending on the media format, security classification, and targeted customer, the end product can be a technical report, software and data sets, or general technology availability notices. Distribution is by traditional hard copy and Internet publishing methods. NASA Langley technical publications are currently distributed on the World Wide Web (WWW) by the Langley Technical Report Server (Nelson, et. al., 1994) and the NASA Technical Report Server (NTRS) (Nelson, et. al., 1995); some software via the Langley Software Server (LSS); and technologies available for licensing via the Technology Opportunity Showcase (TOPS) (Nelson and Bianco, 1994).

This work relation model for aerospace information requires: (1) people to do the work (2) tools to do the job (3) and facilities to house the tools and people. Managing the research and technology process involves allocating varying resources to achieve the optimum relationship between these unique data sets. 


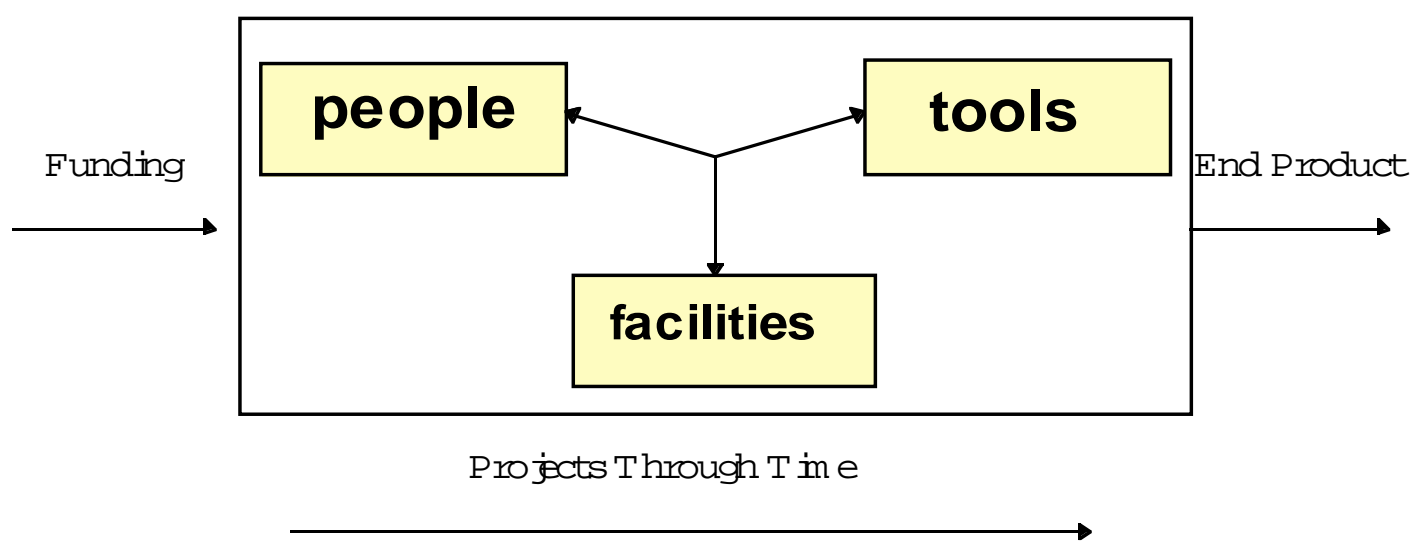

Figure 1: Simple Work Relation Model at Langley

However, decreasing workforce and budgets, coupled with increasing workloads has forced Langley to investigate technologies with a non-linear return on investment. Based upon the success of earlier experiments of using WWW for electronic publishing, increasing WWW usage and focusing it on a few core functionalities was seen as a method to achieve the desired cost savings and efficiency gains.

\section{PROJECT DESCRIPTION}

\section{Overview}

The desire was to build upon the existing TCP/IP infrastructure and budding WWW user community to provide universal access to key services at Langley. The World Wide Web (Berners-Lee, 1992) is a TCP/IP based, wide area hypertext information system that is available for all popular computer platforms: Mac, PC, and Unix. In June 1993 Langley became the first center in the Agency to have a World Wide Web home page for distributing information internally and to the public. Growth of home pages at the center and throughout the world was rapid; Langley web space currently consists of 17,000+ pages, and the entire web is estimated at 50 million pages (Bray, 1996). The rapid growth at Langley, however, was due to the efforts of a few World Wide Web enthusiasts. In early 1995, NASA Langley dedicated 1.5 full-time equivalents to officially handle the integration and coordination of WWW services and facilities. Membership in the team is dynamic and is a grass roots effort, with new members constantly being recruited. The team consists of 13 additional members from across the Center and has occasionally grown to 126 for events such as Internet Fair 2 (See Appendix A for Uniform Resource Locators (URL's)). 
Under this Center-Wide Self-Directed Team approach the WWW team provides vision, develops strategy, and procures resources to implement its mission. The WWW team's mission is "To implement an integrated, easy to use, and cost efficient information environment."

There were a number of distributed WWW activities occurring simultaneously, but there were three that benefited from central coordination and provided significant savings:

LANTERN, Langley's Intranet; Cicero, a software distribution mechanism; and an on-line version of the Langley Master Plan, a facilities and physical plant reference guide. Each of these significant activities corresponds to a component in the work model in figure 1:

LANTERN is an asynchronous communications tool for people, Cicero provides point and click access to software tools, and the on-line Master Plan is a continuously updated record of the physical center and its facilities. Although the 3 projects did not run concurrently, they form the foundation of a holistic information technology strategic plan for Langley.

\section{Technology Concerns}

Technology was not a limiting factor in any of the projects. Aside from having a large pool of creative technical talent at Langley, most of the tools involved in the Master Plan, Cicero and LANTERN were developed wholly or in part by the Internet community at large or were commercial-off-the-shelf (COTS) tools. By leveraging the output of a world-wide development team, creating WWW services becomes largely systems integration, not systems development. Turn-key solutions do not exist freely on the Internet; but their components do. The following is a summary of the technical challenges for each of the project components, with the details appearing in the next section.

For the Master Plan project, the technical challenges were largely database integration, and converting legacy hard copy information to electronic format. Once the information had been extracted from closed, proprietary databases, or converted to electronic form, manipulation of the data is a well understood process.

Cicero required the innovative application of existing Unix tools, with some shell script "glue" to hold it all together. The technology for Cicero has existed for some time, its the defined process available through a well-known, consistent WWW user interface that makes it a full product. 
LANTERN required the least amount of additional technology of all. The very nature of an Intranet dictates the reuse of wide area networking tools in a local area networking scenario (Auditore, 1995; Sprout, 1995). The challenge in establishing a successful Intranet is the social and political groundwork, not the technology.

\section{Management and Organizational Concerns}

Management, organization, and logistical concerns are by far the biggest challenges to an information technology project. In fact, solving the "technical" part of a project is often the "easy" part. Information technology projects impact existing processes and must overcome both those that have a real or perceived interest in existing processes as well as the inertia of human nature. They key to mitigating the resistance to the projects is to involve all stake holders of the existing process early in the planning and development of the information technology project (Moreton, 1995).

In the case of the Master Plan, this involved working with those that operated and maintained hard copy drawings, maps, and various proprietary databases. By involving the current information holders early in the process, resistance to creating an on-line version was minimized.

Cicero illustrates a socio-management challenge on multiple levels. There were many people that had wanted Cicero-like functionality for some time, and eagerly embraced it as soon as it was available. Others were won over through several demonstrations, seminars, and referrals from other users. Even though Cicero is widely praised by all that use it, it has the side effect of serving as a catalyst for existing, unresolved debate in how to handle distributed systems support. So even though a product can meet customer expectations, its impact has to be understood within the larger organizational context.

LANTERN's challenge was similar to Cicero's, but on a larger scale. Not only was a new communications process introduced, but its impact on existing processes had to be clearly communicated to all involved. The LANTERN team accomplished this by first gaining the support of a senior member of management, then publicizing and then holding a number of informal design shop meetings that encouraged employees to contribute suggestions for process improvement at Langley. The suggestions that were within the scope of LANTERN were addressed, and explanation was given for why the remainder were outside the scope of LANTERN. In addition to the design shop meetings, feedback was encouraged via e-mail, hard copy, and telephone. 


\section{CURRENT STATUS OF THE PROJECT}

This section introduces the history and current details about each major component of the WWW project at Langley.

Master Plan

A 1994 survey of the Internal Operations Group identified many problems associated with how institutional information at Langley was gathered, stored, updated, distributed and used. One of the most significant challenges found was that large volumes of data were held in many different formats. As many as 95 different management information systems were in use in the Internal Operations Group (Ball, et. al., 1994). The survey found that these systems were developed with a, "variety of software packages on a variety of platforms." The study also noted, "Many are standalone and unique to functional organizations" and with regard to these systems, "There is a large amount of manual data entry. " This diversity in the location and formats of data as well as the lack of integration of the various systems (as illustrated in Figure 2) makes complex queries (i.e., across multiple databases) very difficult and time consuming. One of these databases was the Master Plan, the architectural blue prints of each building and total center layout for Langley. The Master Plan is a benchmark when new construction or changes need to be done to any of the buildings or adjacent land area.. The Master Plan includes data such as underground utilities, building dimensions, ground composition, title, and abstract data.

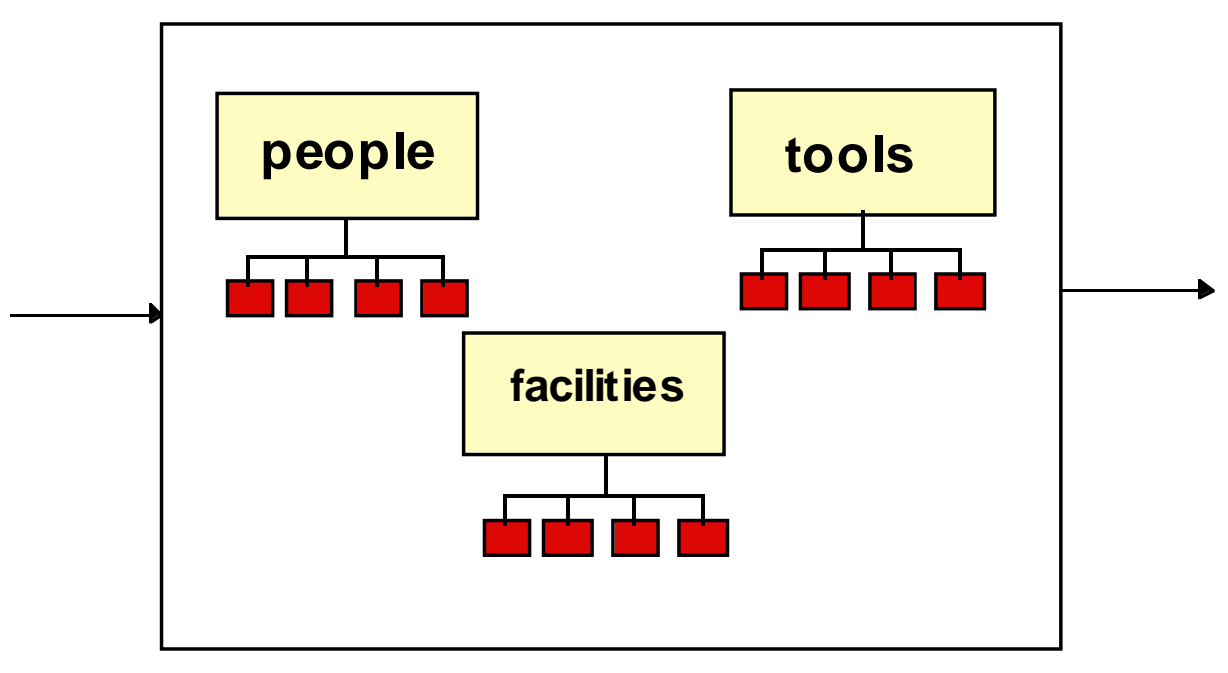

Figure 2: Non-Integrated Databases for Each Component 
The Langley Master Plan had traditionally been produced by hand as a collection of sheets or "plates" which were duplicated and distributed in hard copy form using offset printing. Approximately 70 copies of these tabloid sized booklets consisting of 150 color plates each were distributed for each release. In 1979, the cost for producing the Master Plan was approximately US $\$ 500,000$. Because of this costly and labor-intensive process, the document was only revised every 5 - 10 years. This update schedule was typically "crisisdriven," by events such as major building additions and other large construction projects. Because of this haphazard revision cycle, and because of the document being almost always out of date, the Master Plan was only used as a sort of "coffee table reference" to be marked up by planners wishing to make changes. Actual site planning was done with separate drawings for Preliminary and Critical Design reviews. The nature of the data in the document limited its usefulness as well. The plates, existing only as pictures on paper, could not contain or effectively reference other attribute data. This static format did not enable "what-if" planning or make it easy to visualize or analyze different options. This format also dictated that a completely separate database, existing totally on paper, be maintained for the Master Plan and individual building site plans, since the Master Plan was not drawn to sufficient levels of detail or accuracy to be used as an engineering working document. The level of effort required to produce the Master Plan increased dramatically in 1986 because of escalated requirements for documentation of environmental and historical information. In order to make the Master Plan more current, cheaper to maintain, and carry additional information, it was converted to CADD (Computer Aided Design / Drafting) electronic format beginning in 1989.

The development of this electronic version took place between 1989 and 1992 with a total cost (including printing and distributing 60 copies) of approximately US $\$ 300,000$. The required number of complete copies distributed was reduced by making the electronic drawing files available over the Langley computer network. The level of detail and accuracy of these drawings allowed them to be used for engineering planning, both in the creation of proposed site plans and for discussion in design reviews. This alleviated the need for separate drawing databases and the extra maintenance associated with multiple copies.

The ability to associate these drawings with additional features such as environmental and historical data allowed other organizations outside the Master Planning office to use them for reference and analysis. This electronic Master Plan was demonstrated to a NASA-wide "lessons learned" conference as a model for the other centers to strive toward. Even though this migration to electronic files was a necessary and cost-effective step, the 
emergence of new technologies for handling spatial data would prove to eclipse this version with even greater savings and more useful data. This new technology, Geographic Information Systems would revolutionize the way planners at Langley thought about maps.

Begun around 1993 as a prototype of a future Master Plan, this transition to GIS has been accepted as the latest incarnation of this "document." Actually, Master Plan is really a database, tying together electronic drawing sets and tabular data into a seamless hierarchical system of information gathering, display, and analysis. Unprecedented accuracy is possible through the use of digital aerial photography and Global Positioning System (GPS) data, which can be readily assimilated into the system. Through the use of appropriate queries, the separate plates of the old Master Plan can be generated, but the real power of this system is to allow detailed analysis and scenario planning using any number of variables, data relationships, and constraints.

By integrating the graphical databases of underground utilities, building layouts, environmental zones, roads, etc., with tabular databases such as personnel information, space utilization, energy metering, and real property, the GIS Master Plan allows complex analysis and planning to be easily performed in a fraction of the time. This data can now be used for tasks which were all but impossible before. The system was recently used to settle a 20 year old dispute over some remote property used by Langley for drop model testing. Using the aerial photos, GPS surveys, and property and tax maps digitized into the system, property boundaries were precisely located, and plots generated which convinced a Federal judge that Langley was the legal owner of the property in question. During the threat of hurricane Felix in the September of 1995, flood contours and building outlines were used to determine where to place sandbags, and what equipment to elevate and how high, to minimize water damage.

Not only has the Master Plan database become a much more useful planning and response tool, it has truly become the most current source of spatial information at the center. Because live links to various databases are used to gather information on demand, every query is answered with the latest data from every source. The GIS version of the Master Plan was developed between 1993 and 1996 at a cost of less than US \$70,000. The decreasing cost of producing the Master Plan in various formats is shown in Figure 3. The ability to perform queries and view result over the LaRCNET network has drastically reduced the need for printed copies. Individual users can print a report as needed at their local printer, and almost no one needs a print of the entire database. Although network access has made the Master Plan available and useful to a much greater user community, 
some training and computer expertise is required to effectively use the system. That is changing rapidly through the development of World Wide Web based tools and services.

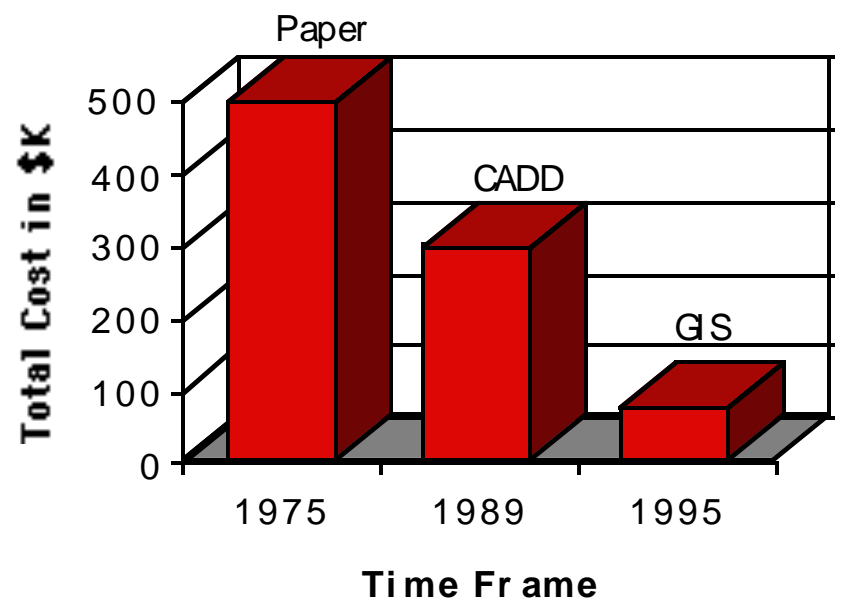

Figure 3: Decreasing Master Plan Cost

\section{Cicero}

Historically, distributed computing at Langley has been a collection of small groups of computers, separately maintained and staffed by individual branches or projects, held together by a center-wide TCP/IP backbone. Little work sharing existed between the individual system administrators, especially those employed by different organizations. The Langley Computer Users' Committee (LCUC) was established to provide a unified voice for Langley users to provide their requirements to the computing center. Under its auspices, the Distributed Systems Subcommittee provided a way for system administrators to get to know each other and to cooperate in order to provide better service to their users.

The LCUC and its various subcommittees have proved enormously successful. LCUCsponsored user's groups and initiatives have helped individual system administrators stay current with the important computing issues at Langley. In addition, they offer a repository of sources and binaries for popular software packages, which has been one of their most successful offerings. It represents a form of load-balancing among the system administrators. Unfortunately, the software is considered "unsupported." Anyone at Langley who wishes can contribute to the archive, but there is no way to determine if the software they configured and compiled will work on any other given system. The system 
administration methods at Langley vary widely, and software configured for one set of machines may not be suitable for another. Thus, the load-balancing provided by these software archives, while useful, is not quite as useful as it could be if common configuration differences were overcome.

To help overcome these problems, Langley formed the Integrated Computing Environment (ICE) team in late 1993. ICE's objectives are twofold: the first is to provide a common computing environment on each of the major platforms in use. By providing a common set of software tools across all platforms, users will feel comfortable no matter what hardware or OS is being used. The second objective is to ease the administrative burden on the maintainers of these systems. We accomplish this by serving as a clearinghouse for important tools and information for example, vendor security information and by providing optional standards for system installation and configuration.

In February 1994, the ICE team started to look seriously at the problem of providing stable, pre-configured versions of its Unix software for use by the Langley community. Learning from and building upon the success of the LCUC software archive, the ICE team offered a set of applications and software that is made available on each of the widely used platforms at Langley. The team projected that some system administrators would prefer to get their entire /usr/local partition from ICE through a method such as Rdist (Rdist is a Unix program to maintain identical copies of file over multiple hosts) that are executing that would serve to keep them tightly in sync with the latest supported versions of the software for their platform. The ICE team recognized, however, that this would not be the normal case. Most system administrators would prefer to retain the privilege of determining exactly what software is present on their systems rather than trust an automated method. Cicero was born out of this need to provide a solution that would address those concerns, while still providing an easy, semi-automated method of acquiring supported ICE software.

Using the WWW method, administrators can use WWW clients to browse the list of supported software for their particular hardware and operating system combination. Clicking on the software's name will download the package information file and cause ciceinst (Cicero install) to run on the local machine. Because the package files have digital signatures there is no possibility of accidentally installing malicious software. If the package is not signed correctly, ciceinst refuses to proceed with the installation. 


\section{LANTERN}

NASA Langley Web activities prior to the summer of 1995 were largely constructed for external customers. However, a growing number of information resources that were not appropriate or applicable for external dissemination were becoming common. At that time, the WWW Team decided that a separate information space was necessary dedicated to the business of doing business inside Langley. WWW and computer networks were no longer the domain of the computational scientists, but all organizational users could now access information of interest to them on the internal web pages (Sprout, 1995). LANTERN is Langley's Intranet (LANgley inTERNal home page.) LANTERN's value is that an employee can access institutional knowledge and initiate processes from their desktop 24 hours a day seven days a week ("is Bob in this week?") and "storage" of information ("Where did I put that notice, I can't find anything on my desk?") is provided in a single well known location. In order to build an effective Intranet the team also recognized that there were a number of activities that needed to be done to ensure successful integration of an Intranet into Langley's work environment, most importantly training.

The WWW team developed a 2 hours training class taught by volunteers to give instruction to the entire center on the fundamentals of the Internet and WWW browser Navigation. During the first offering of classes 288 slots were filled in less than 2 hours and 265 people were place on waiting list. The team then scheduled two 1 day retreats. On May 23, 1995, the WWW team met to develop the design requirements and work out the process methodology for gathering for customer requirements for the center's Intranet. The three significant design goals that came out of the process were: it must be easy to use by all; it must be easy to maintain; and it must provide useful information that employees want.

To gather data an electronic message was sent to the entire center explaining what an Intranet was, how it would streamline administrative processes, and how they could participate. The team also scheduled five 2 hour round table discussions open to the entire center for requirements gathering. Equipped with the data from the first retreat, collected email, and data gathered from the round table discussions, the team met two weeks later for an all day retreat to analyze and process all data into categories and develop the initial architecture for LANTERN.

The WWW team felt that it needed to inform most potential users and so the Researcher News, the center's bi-weekly publication was asked to participate in the design process. Timed very closely with the first release of LANTERN, June 13, 1995, was a two-page 
article in the center's bi-weekly newsletter explaining LANTERN, its scope, and how interested employees could participate.

\section{SUCCESSES AND FAILURES}

\section{Master Plan}

In 1995, Langley was beginning to use the Web as an Intranet tool for many of its internal data services. It was apparent that the ideal way for the largest number of users on various computing platforms to use the Master Plan and other GIS data was to make them accessible through WWW browsers. The first such a service was the Langley Building and Room Locator. This interface presents a form to the user into which a building number and room number are entered, and maps of both the building and room are pulled from the GIS database and presented on the user's WWW browser.

This service has been made a part of the Langley electronic post office, also Web based, which allows a search by name, e-mail address, etc. and after presenting the address, organization, phone number, and other pertinent contact information, the user can access the Building and Room Locator to find that person's office. Since live database connections are used, and the maps and building drawings are generated on the fly, the system automatically shows the current room assignment, correct building, etc. This is a limited use of GIS on the Web, but it is a proof of concept for the eventual interface to the Master Plan. Users will be able to perform complex queries on multiple data sets and generate specific graphics that show the relationships between those data sets. Information such as energy use by building, maintenance costs per organization, population density within buildings, and even combinations of those data will be available, forming the core of a decision support system for downsizing, building closure planning, consolidation of similar spaces, personnel relocation planning, etc.

With sufficient "hooks" into many databases, the types of information available are nearly unlimited. Eventually, updates to the database will be possible using advances in WWW technology and digital signature and authentication techniques. This will allow anyone to maintain their data with little training. Because of this universal accessibility, the data will converge to greater accuracy, since each user will be interested in correcting the particular information associated with their facility or function. It is anticipated that a significant number of possible queries will be available over the WWW before 1997. Hopefully, with easy access to the Master Plan, hard copy distributions will be not be needed again. The Master Plan will evolve into a complete, detailed virtual model of Langley that is always up 
to date, available to everyone, and sophisticated enough to answer any question about the people and infrastructure of the center.

\section{Cicero}

Cicero has been very well received by the Langley community. There was, however, one unanticipated objection to providing this service. During an informal presentation of Cicero to one of the LCUC subcommittees, it was pointed out that we had perhaps made software "too easy" to install. System administration methods vary widely at Langley. In many places, users have root access in order to perform certain tasks relating to their research (e.g., loading a real-time sensor device driver). If Cicero provided an easy to use "Click to Install" method of updating system binaries, would the users not be tempted to install any piece of software that looked interesting to them? Potentially, this could cause such problems as filling up available disk space or catching other users by surprise when a piece of software is suddenly upgraded to a newer, slightly different, version.

This is, unfortunately, a symptom of a more serious problem: users who have root access yet cannot be trusted to use it wisely. For Cicero, a compromise was available. Cicero uses the syslog facility to log a message each time a software package is installed. While this does not prevent users with root access from installing software on their own, it does provide a useful audit trail.

The system administration community gives Cicero high acclaim because saves significant time and frees them to do other work without worrying about the chore of software installation. In the 10 hours it takes to build and install X Window System, they can help users, re-configure workstations, etc. Users also are pleased with this concept, since it means they receive much more personal attention from their system administrator. Package installation systems like Cicero are time savers for large sites with distributed system administration tasks. Langley has already seen significant cost savings. Packages that used to take 3 hours for an experienced system administrator to install now takes 2 minutes.

\section{LANTERN}

LANTERN quickly integrated into Langley culture. Through the outreach efforts, people took ownership in LANTERN and enthusiastically contributed to the services available, a sample of which is in Table 3. 
In November, 1995 the weekly newsletter ceased hard copy circulation and is available only through LANTERN, at an annual cost savings of US $\$ 25,000$. In addition, the editor of the newsletter has reduced preparation time of each issue from 1.5 days to 2 hours. The center is also transitioning all small purchases to a WWW transaction based system. This service will become available in April 1996 and the estimated annual cost saving is US $\$ 100,000$. Significant cost reductions are being realized from the elimination of redundant paper processing with the center's Management Instructions Manuals. Secretaries no longer have to spend time replacing outdated sheets in the Management Instruction Manual binders with updated versions. This is significant in that there is at least 50 copies of the Management Instructions Manuals across the Center and each need to be kept up to date. On average a secretary spends an hour a week on this activity. Keeping all 50 sets up to date used to consumer nearly a collective person-year! Also eliminated are costs incurred from making the initial copies and mailing them to all offices that have manuals.

\begin{tabular}{|l|l|}
\hline 1. & Forms (81 currently used Center-wide) \\
\hline 2. & Health Services \\
\hline 3. & Holiday and Payroll dates \\
\hline 4. & How Do I ? (by subject, computers, procurement, printing; publishing, scheduling; reservation) \\
\hline 5. & Idle Property Screening List \\
\hline 6. & Instructions for putting a paper on Langley Technical Report Server (LTRS) \\
\hline 7. & Intranet feedback form \\
\hline 8. & Inventory Database \\
\hline 9. & Job Order Numbers \\
\hline 10. & Langley Activities Association (Intramural Activities) \\
\hline 11. & Langley Child Development Center \\
\hline 12. & Langley Federal Credit Union \\
\hline 13. & larc.announce (newsgroup which archives all messages sent Center-wide) \\
\hline 14. & LaRC Street Map \\
\hline 15. & LaRC This Week (Weekly Newsletter) \\
\hline 16. & LaRC Townmeeting Question Form \\
\hline 17. & Institutional Studies Library \\
\hline 18. & Recycling Information \\
\hline 19. & Services Directory \\
\hline 20. & Software License Information \\
\hline
\end{tabular}

Table 3: 20 of the 60+ LANTERN Services 
New communications tools create new communications patterns (Evard, 1993). The most obvious communications shift caused by WWW and LANTERN is that people are comfortable with passing pointers to information collections, instead of trying to pass entire data object(s) through e-mail, hard copy, conversation, etc. This lessens the effort required for certain communication tasks and encourages more data sharing. There has been a tremendous growth of sharing of information in the past year. Many databases where information was solely the domain of a particular organization are now available to the entire Center. For example, there is an equipment database that tracks who owns what equipment and where it is located. Previously an employee had to call the inventory office or and fill out a form to request an inventory of equipment. Now it is possible to query the equipment database in 12 different ways and get the data on-line in a matter of seconds.

Another time saving device is the Center's electronic post office which started out as an X.500 server then subsequently was ported to the Web with necessary common gateway interface (CGI) scripts to incorporate the building and room locator service (Master Plan data). Currently, the electronic post office has 10,000+ accesses weekly. It is also noteworthy that the Center telephone directory is printed once ever year and half at a cost of US $\$ 15,000$ and is out of date the moment its printed. However, the electronic post office receives weekly downloads from the Personnel database and automatically does its updates at virtually negligible cost. Its these types of efficiencies that is maximizing information sharing among employees and increases work productivity while cutting costs.

Not exactly a failure, but a situation to be aware of is the cost of success. LANTERN has been successful, but it also raises expectations in the user community. Users, encouraged by the usefulness of the initial Intranet, expect that anything can be done for everyone. Setting priorities and curbing expectations are difficult management tasks that occur in the wake of a successful project.

\section{EPILOGUE AND LESSONS LEARNED}

Through the Master Plan, Cicero, LANTERN, and the other related WWW projects, we have found that there are 4 pillars that are key to information technology project success (Figure 4): 


\section{Training}

How to use emerging information technology tools

Providing Useful Services

Services Langley's staff needs and wants

\section{Enabling Tools}

Providing information access tools to the customers

Advertising and Advocacy

NASA's products and services around the nation and internally

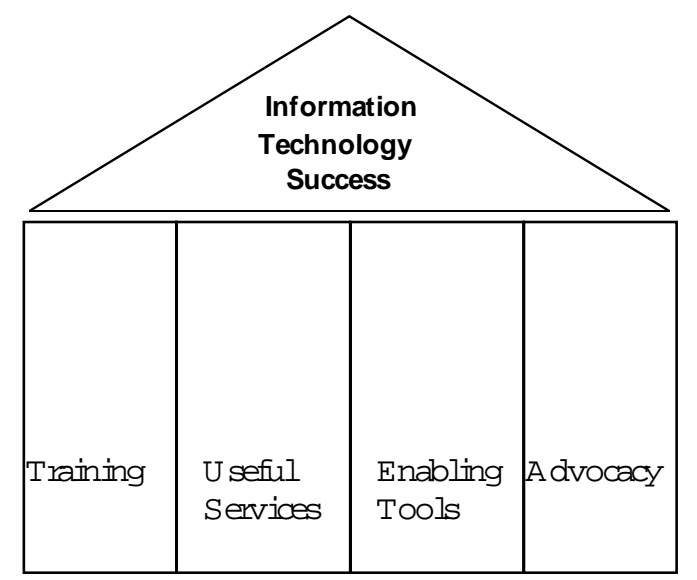

Figure 4: Four Pillars of Information Technology Success

By applying resources equally across each pillar, the Master Plan, Cicero and LANTERN have been successful individually, and have provided the foundation for a large strategic information interchange infrastructure for the center. Table 4 shows major activities for each project component and it is measured impact for people at Langley and the external customers. 


\begin{tabular}{|c|c|c|c|}
\hline Area & Activity & $\begin{array}{c}\text { Participating } \\
\text { Team } \\
\end{array}$ & $\begin{array}{c}\text { Number of } \\
\text { People Reached }\end{array}$ \\
\hline \multirow[t]{3}{*}{ Training } & WWW browser training classes & WWW, GIS & 750 \\
\hline & 3 WWW reference sheets & WWW & 1,500 \\
\hline & WWW browser training video & WWW & 500 \\
\hline \multirow[t]{6}{*}{ Services } & NASA Technical Report Server & WWW & 100,000 \\
\hline & Langley Software Server & WWW, TAG & 1,000 \\
\hline & $\begin{array}{l}\text { Technology Opportunity } \\
\text { Showcase on-line }\end{array}$ & WWW, TAG & 15,000 \\
\hline & LANTERN - Langley's Intranet & ICE, GIS , WWW & 5,000 \\
\hline & WWW caching server & ICE & 5,000 \\
\hline & Building \& Room Locator & GIS & 15,000 \\
\hline \multirow[t]{2}{*}{ Enabling Tools } & Netscape Site License & WWW & 2,500 \\
\hline & MacHTTP Site License & WWW & 300 \\
\hline \multirow[t]{4}{*}{ Advocacy } & TOPS '95 & WWW, ICE, GIS, TAG & 2,500 \\
\hline & Oshkosh '95 & WWW, K-12, TAG & 10,000 \\
\hline & Internet ' 95 & WWW, GIS, ICE & 400 \\
\hline & Internet Fair 2 & WWW, GIS, ICE & 2,000 \\
\hline
\end{tabular}

\section{Table 4: Activities and the Impact Chart} March 1, 1995 -- December 1, 1995

The WWW, GIS, and ICE project teams have already been introduced. TAG and K-12 refer to the technology transfer and educational outreach project teams, respectively.

Specific lessons we would give to others considering integrating information technology into their business environment include:

\section{Get a strong Senior Management sponsor with resources}

WWW efforts have the highest probability of success when they begin as grass roots

efforts, develop a small number of success stories, and then sell the concept to a sympathetic member of senior management. It is inevitable that WWW successes will be viewed as threats (real or imagined) by other members of the organizations, and a sponsor offers a greater level of protection. 
Find someone who is a WWW evangelist with leadership skills

Until a WWW effort is institutionalized, success is dependent on generally a single person who can both produce useful WWW services with limited resources while enduring changing perceptions of WWW technologies, from "when will this silver bullet fix my problem" to "WWW is a waste of time".

\section{Train everyone how to use your tools and services}

Just as nearly all employees are both consumers and producers of information in traditional media formats, the same holds true for electronic format. It is everyone's responsibility to both use and contribute to an organizations information space.

\section{ADVERTISE, ADVERTISE, ADVERTISE and then ADVERTISE some more}

Advertisement and outreach is a never ending effort. The resources required will go down when critical mass is required, but it is never "done." A danger to watch out for is that the technical organizations that generally assist in the development of WWW resources are generally unskilled in the advocacy of such resources, especially to non-technical customers.

\section{Find and GET the best technical support you can find}

Services that are down, unavailable, or stale can do more harm than good. Enlist the best technical people possible, but ensure they have the commitment necessary for information maintenance.

World Wide Web has been the catalyst for many Information Technology projects at NASA Langley. The Master Plan, Cicero, and LANTERN are selected because they support each segment of the NASA Langley Work Relation Model; Facilities, Tools, and People respectively. For providing useful services, the focus for the future is to integrate more Master Plan data, push for wider application of Cicero, and transition more hard copy administrative data to LANTERN. Langley's Intranet continues to grow, with even more procurement and tracking services slated for WWW interfaces. For training, in March 1996 the Center began HTML authoring classes. For enabling tools, an Agency-wide site license for Netscape has been purchased. Advertising and outreach continues at every possible center event and at a personal, one-on-one advocacy and education. How do you know you have succeeded? When phrases such as "Well we can just put it up on LANTERN" are commonly overheard in the cafeteria. 


\section{Appendix A: URL's of Listed Resources}

\begin{tabular}{ll}
\hline \multicolumn{1}{c}{ Resource } & \multicolumn{1}{c}{ Uniform Resource Locator } \\
\hline Building and Room Locator & http://gis-www.larc.nasa.gov/cgi-bin/locator \\
Cicero & http://ice-www.larc.nasa.gov/ICE/doc/Cicero/ \\
Integrated Computing Environment & http://ice-www.larc.nasa.gov/ICE/ \\
Internet Fair 2 & $\mathrm{http} / /$ www.larc.nasa.gov/if// \\
Langley Computer Users Committee & $\mathrm{http} / / / \mathrm{cabsparc}$ larc.nasa.gov/LCUC/lcuc.html \\
Langley Home Page & $\mathrm{http} / /$ www.larc.nasa.gov/ \\
LANTERN & (restricted access) \\
Master Plan & $\mathrm{http://gis-www.larc.nasa.gov/}$ \\
Post Office & $\mathrm{http} / / /$ post.larc.nasa.gov/cgi-bin/whois.pl \\
WWW Training & $\mathrm{http}: / /$ boardwalk.larc.nasa.gov/isd-www/training.html \\
\hline
\end{tabular}

\section{DISCUSSION QUESTIONS}

1. The focus of this paper has been mostly applicable to large organizations. How would the issues, resolution, and services presented here be applicable to small organizations? What would be the same? What would not be applicable? What new challenges would exist that large organizations do not face?

2. WWW and related technologies are often applied to integrating a number of legacy database systems. If an organization could start with a clean slate, what would be an appropriate Information System architecture and what role would WWW play in the new system?

3. The Master Plan and related geographic information systems showed a clear path of evolution from hard copy to initial WWW interface. Discuss how a traditional Management Information System would make such an evolution. What additional security or privacy issues are introduced by the switch to Management from Geographic data?

4. The NASA Langley WWW Team proposed the "Four Pillars of Information Technology Project Success" which are: Training, Developing useful services, Providing enabling tools, and Advertising available resources. Discuss this 4 pronged model. Are there additional pillars? Could the model be simplified to fewer pillars? Are there cases where the 4 pillars could be fully satisfied, but a project could fail?

5. The concept was introduced of a grass roots team or project transitioning to official status with senior management approval and sponsorship. What is the best time for this transition to take place? What are the dangers of it occurring too early? Too late? What (if any) about this concept is applicable only to Information Technology projects? 


\section{REFERENCES}

Auditore, Peter (1995). "Weaving a web inside the corporation: The future of collaborative computing," Computer Technology Review, Summer-Fall 1995, pp. 14-17.

Ball, W. Brad, Meyer, John M. \& Gage, Robert L. (1995). "GIS Business Plan", NASA Langley Research Center. URL: http://gis-www.larc.nasa.gov/bplan/

Berners-Lee, T., Calliau, R., Groff, J. F., \& Pollermand, B. (1992), "World-Wide Web: the information universe," Electronic Networking: Research, Applications, and Policy, 2(1), 52-58.

Bray, Tim (1996). “Measuring the Web”, World Wide Web Journal, 1(3), pp. 141-154.

Evard, Remy (1993). "Collaborative networked communication: MUDs as system tools," Proceedings of the 7th System Administratoin Conference (LISA '93), Monterey, CA, November 1-5, 1993, pp. 1-8.

Moreton, Robert (1995). "Transforming the organization: the contribution of the information systems function," Journal of Strategic Information Sysetms, 4, pp. 149-164.

Nelson, M. L., Gottlich, G. L., Bianco, D. J., Paulson, S.S., Binkley, R. L., Kellogg, Y. D., Beaumont, C. J., Schmunk, R. B., Kurtz, M.J., Accomazzi, A. \& Syed, O. (1995). "The NASA Technical Report Server", Internet Research: Electronic Network Applications and Policy, 5(2), pp. 25-36.

Nelson, Michael L. \& Bianco, David J. (1994). "The World Wide Web and technology transfer at NASA Langley Research Center," Proceedings of the Second International World Wide Web Conference, Chicago, IL, October 18-20, 1994, pp. 701-710.

Nelson, Michael L., Gottlich, Gretchen L., \& Bianco, David J. (1994). "World Wide Web implementation of the Langley Technical Report Server ", NASA TM-109162.

Office of Public Affairs, NASA Langley (1995). "NASA Langley Fact Sheet" URL: http://www.larc.nasa.gov/org/pao/PAIS/Langley.html

Shoosmith, John (1993). "Introduction to the LaRC Central Scientific Computing Compex," NASA TM-104092.

Sprout, Alison (1995). “The Internet inside your company,” Fortune, 132(11), pp. 161-168.

Wieseman, Carol D. (Ed.) (1994). "The role of computers in research and development at NASA LangleyResearch Center,” NASA CP-10159. 


\section{GLOSSARY}

Cicero - a World Wide Web based UNIX software distribution system developed at NASA Langley Research Center.

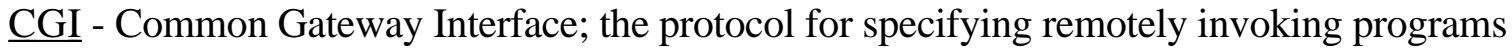
on World Wide Web servers.

GIS - Geographic Information Systems; a collection of databases, information systems, and techniques for managing and modeling the state of a physical location, such as a building, county, roads, etc.

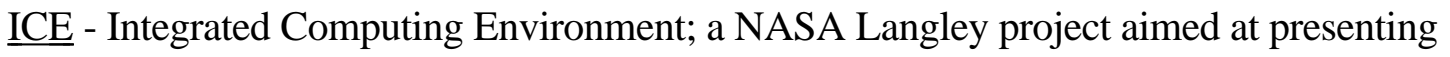
computer users with a uniform and extensible interface to their environment and resources while decreasing the system administration effort required to manage remote systems.

Intranet - A term describing using TCP/IP and Internet tools and techniques primarily for internal organizational communications usage.

Internet - A global network of interconnected networks that all use the TCP/IP communications protocol.

LANTERN - The name of NASA Langley Research Center's intranet.

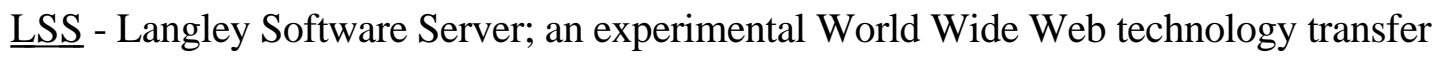
resource at NASA Langley for customers to receive or order NASA software available for distribution.

Master Plan - The canonical reference document describing the state of all NASA Langley buildings, and surrounding resources.

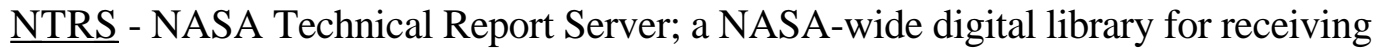
unclassified NASA technical publications

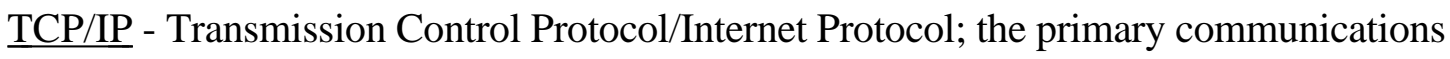
protocol that allows computers on the Internet to communicate with each other. 
TOPS - Technology Opportunities Showcase; a technology transfer conference held at NASA Langley Research Center that was later converted to a World Wide Web database.

UNIX - A complex, multi-user operating system frequently employed in academic departments, scientific laboratories, and other areas of intensive use.

URL - Uniform Resource Locator; an address that specifies a unique location of a resource on the Internet.

USENET - A global news system arranged in subject hierarchies. Allows submission and reading of articles over a nearly unlimited breadth of topics.

$\underline{X .500}$ - An international standard for implementing directory services for organizations. Often used to look up people's e-mail addresses, telephone numbers, and other public attributes. 
Gretchen L. Gottlich <ggottlich@fruit.com> received a M.L.S. in library and information science from Indiana University in 1991, and a B.S. in geography \& urban affairs in 1985 from the University of Arkansas. Gretchen's principal contributions at NASA included digital library work and World Wide Web team management. The latter involved such projects as the implementation of the NASA Langley intranet, the organizing of two NASA Langley Internet Fairs, the design of World Wide Web training modules, insuring computer access to over 800 NASA Langley technicians, and numerous internal and external presentations about NASA Langley Internet resources. In July 1996, Gretchen joined Fruit of the Loom as a senior information technology analyst.

Michael L. Nelson <m.1.nelson@larc.nasa.gov> graduated with a B.S. in computer science from Virginia Tech and is a graduate student in computer science at Old Dominion University. Since coming to work for NASA Langley Research Center's Information Systems Division in September of 1991, Michael has worked on a variety of projects in the distributed and parallel computing, distributed information systems, and computing environments areas. He is the "webmaster" for NASA Langley Research Center and has worked with others to implement report servers, software servers, technology transfer databases and other World Wide Web services. He has over 20 technical publications and presentations about distributed and parallel computing and information systems.

John M. Meyer <j.m.meyer@larc.nasa.gov> received a B.S. in electrical engineering from Virginia Tech in 1985. John has been active in numerous areas at NASA Langley, including CADD, design of real-time video and data acquisition systems, geographic information systems both with NASA and the United States Air Force, and network information systems.

David J. Bianco <d.j.bianco@larc.nasa.gov> began working for Computer Sciences Corporation in November of 1993. David has assisted NASA Langley's Information Systems and Services Division in many areas, including standards-based computing environments, distributed information systems, cryptography, the Distributed Computing Environment / Distributed File Service (DCE/DFS), and his work on the Integrated Computing Environment team. David has previously held positions at the Old Dominion University and iTRiBE. 